\title{
A prospective analytical study of intrauterine fetal death cases and associated maternal condition at a tertiary centre
}

\author{
Hanslata Gehlot*, Girdhar Gopal Nagar, Seema Sharma, Om Prakash Yadav
}

Department of Obstetrics and Gynecology, Dr. S. N. Medical College, Jodhpur, Rajasthan, India

Received: 06 April 2017

Revised: 21 June 2017

Accepted: 24 June 2017

\author{
*Correspondence: \\ Dr. Hanslata Gehlot, \\ E-mail: pummyia@gmail.com
}

Copyright: (c) the author(s), publisher and licensee Medip Academy. This is an open-access article distributed under the terms of the Creative Commons Attribution Non-Commercial License, which permits unrestricted non-commercial use, distribution, and reproduction in any medium, provided the original work is properly cited.

\begin{abstract}
Background: Intrauterine fetal death (IUFD) is a cataclysmic event for the parents and a lamentable event for the caregiver. Intrauterine fetal death is an important indicator of maternal and perinatal health of a given population. This study was undertaken to study the maternal and fetal factors associated with intrauterine fetal death. In this traumatic time, it is important to ensure that the emotional needs of the family are met. The objective of the study was to evaluate and understand the prevalence, socio-epidemiological and etiological factors of IUFD.

Methods: This was a prospective analytical study carried out at Umaid Hospital associated to Dr. S. N. Medical College, Jodhpur, Rajasthan from August 2015 to Jan 2016 for a duration of 6 months. Informed consent was taken from all the participants. A predesigned proforma was used to collect relevant information from all those who gave consent to participate in the study. The details of complaints at admission, obstetrical history, menstrual history, examination findings, per vaginal examination findings, mode and method of delivery, and fetal outcome and investigation reports were recorded.

Results: A total of 435 intrauterine fetal deaths were reported amongst 11615 deliveries conducted during the study period in our hospital. The incidence of IUFD was 37/1000 live births. $327(75.17 \%)$ deliveries were unbooked and unsupervised and had no antenatal check-up. 306(70.74\%) patients were from rural areas and $243(50.11 \%)$ were preterm and 430(98.85\%) were singleton delivery. Amongst the identifiable causes, hypertensive disorders $(22.75 \%)$ and very severe anaemia (13.10\%) were the most common ones followed by placental causes $(9.97 \%)$. Congenital malformations were responsible for $11.03 \%$ cases of IUFD and in rest $10.57 \%$ cases no obvious cause could be identified. Induction was done in 195 patients, 174 patients had spontaneous onset of labour and caesarean section was done in 66 patients.

Conclusions: The incidence of intrauterine fetal deaths in our population is higher than that reported from the developed countries. The present study is an effort to compile a profile of maternal, fetal and placental causes culminating in IUFD at our centre. This emphasizes the importance of proper antenatal care and identification of risk factors and its treatment. Institutional deliveries should be promoted to prevent IUFD. Decrease in the incidence of IUFD would significantly reduce the perinatal mortality. Majority of fetal wastage can be prevented with universal and improved antenatal care.
\end{abstract}

Keywords: Anaemia, Congenital malformations, Hypertensive disorders, Intrauterine fetal death

\section{INTRODUCTION}

Intrauterine fetal deaths (IUFD) are the principal subject of concern among obstetricians and paediatricians. ${ }^{1}$ The time following a fetal death is extremely difficult for both the family and the health care providers. According to the 2003 revision of the Procedures for Coding Cause of Fetal Death Under ICD-10, the National Centre for 
Health Statistics defines IUFD as death prior to the complete expulsion or extraction from its mother of a product of human conception, irrespective of the duration of pregnancy and which is not an induced termination of pregnancy.

For statistical purposes, fetal losses are classified according to gestational age. A death that occurs prior to 20 weeks gestation is usually classified as a spontaneous abortion while those occurring after 20 weeks of fetal weight of more than 500 grams constitute a fetal demise or IUFD. The frequency of IUFD varies worldwide, this rate considerably depends on the quality of medical care available in the country in question and the definitions used for classifying fetal deaths. ${ }^{1}$ Underreporting in developing nations like India is common, which makes comparisons even more difficult.

There are so many maternal conditions and diseases that are responsible for poor obstetrical outcomes. The aetiology of fetal demise is unknown in $25-60 \%$ of all cases. In cases where a cause is clearly identified, the cause of fetal death can be attributable to fetal, maternal, or placental pathology. By routine and regular antenatal check-ups, the high-risk cases associated with poor outcomes can be identified.

An antepartum and intrapartum fetal deaths together constitute a large portion of perinatal mortality. Antepartum foetal deaths contributes to $2 / 3^{\text {rd }}$ of perinatal mortality and is major cause of pregnancy wastage. The mode of antepartum and intrapartum surveillance for fetal wellbeing has advanced in last few decades.

The objective of the study was to analyse the maternal conditions associated with intrauterine fetal death with specific reference to clinical presentations, maternal complications and to find the preventable causes of fetal death.

\section{METHODS}

This was a prospective analytical study aimed to evaluate and understand the prevalence, epidemiological and etiological factors, clinical profile of IUFDs from August 2015 to Jan 2016 (6 months' study) which was conducted at Umaid Hospital, Dr. S. N. Medical College, Jodhpur, Rajasthan.

Patients were thoroughly interrogated and systematically examined and optimally investigated and all the findings were recorded on a predesigned proforma. Informed written consent was obtained from all the participants. The patients mainly presented with chief complaints of decreased or loss of fetal movements, history of leaking, bleeding per vagina. The obstetrical history included parity, abortions, stillbirth, neonatal death, lower segment caesarean section (LSCS), preterm delivery, antepartum haemorrhage (APH) or any other medical disorder in previous pregnancy. History regarding her menstrual cycles, past history, personal history was also elicited and noted in the proforma. General examination, local examination findings, per vaginal examination, mode of delivery was done thoroughly. Relevant investigations were also done.

All the women with gestational period beyond 20 weeks to full term pregnancy having normal/malformed foetus were included in the study. The records of babies born below 20weeks of gestation, fetus weighing below $500 \mathrm{~g}$ were excluded from the study.

\section{RESULTS}

The present study consisted of 435 cases of IUFD which occurred during the study period of 6 months. A total of 11615 deliveries occurred in our institute during the study period. The incidence of IUFD was 37.45 per 1000 live birth.

Table 1: Distribution of cases according antenatal booking.

\begin{tabular}{|lll|}
\hline Cases & Number \% & \\
\hline Unbooked & 327 & 75.18 \\
\hline Booked & 108 & 24.82 \\
\hline Total IUFD & 435 & \\
\hline
\end{tabular}

There were total 435 IUFD cases in which 327 (75.18\%) patients were unbooked with no antenatal visits and rest $108(24.82 \%)$ cases were booked patients (Table 1$)$.

Table 2: Distribution of cases according area.

\begin{tabular}{|lll|}
\hline Area & Number $\%$ & \\
\hline Rural area & 306 & 70.34 \\
\hline Urban area & 129 & 29.65 \\
\hline
\end{tabular}

Out of total IUFD cases, $70.34 \%$ of the patients were from the rural areas (Table 2).

Table 3: Distribution of cases according to maternal age.

\begin{tabular}{|lll|}
\hline Age (years) & Number & $\%$ \\
\hline$<20$ & 86 & 19.77 \\
\hline $20-25$ & 217 & 49.39 \\
\hline $26-30$ & 92 & 21.14 \\
\hline $31-35$ & 32 & 7.35 \\
\hline $36-40$ & 6 & 1.38 \\
\hline$>40$ & 2 & 0.45 \\
\hline
\end{tabular}

Table 3 shows that majority of the foetal deaths $(70.53 \%)$ occurred in women between 20 to 30 years of age and minority of the foetal deaths $(0.45 \%)$ occurred in women above 40 years of age.

The majority $168(38.62 \%)$ of women were primigravida (Table 4). 
Table 4: Distribution of cases according parity.

\begin{tabular}{|lll|}
\hline Parity & No. & $\%$ \\
\hline G1 & 168 & 38.62 \\
\hline G2 & 113 & 25.98 \\
\hline G4 & 60 & 13.79 \\
\hline G5 & 46 & 10.57 \\
\hline G6 & 26 & 5.98 \\
\hline G7 & 15 & 3.44 \\
\hline
\end{tabular}

Table 5: Distribution of cases according to past catastrophic obstetric event.

\begin{tabular}{|ll|}
\hline Past obstetric history & No. of patient \\
\hline H/o abortion & 5 \\
\hline H/o IUFD & 39 \\
\hline
\end{tabular}

Table 5 shows that there was past obstetric history of IUFD in 39 cases and abortion in 5 cases and in rest 391 females, the past obstetric history was uneventful.

Table 6: Distribution of cases according no. of foetus.

\begin{tabular}{|lll|}
\hline Type of pregnancy & No. & $\%$ \\
\hline Singleton & 430 & 98.85 \\
\hline Twin & 5 & 1.15 \\
\hline
\end{tabular}

Table 6 shows that majority of the patients who were admitted in hospital presented with singleton 430 $(98.85 \%)$ pregnancy while $5(1.15 \%)$ were multifetal gestations, all of them being twins.

Table 7: Gestational age distribution of IUD fetus.

\begin{tabular}{|lll|}
\hline $\begin{array}{l}\text { Gestational age of } \\
\text { IUD foetus in weeks }\end{array}$ & No. of cases & $\%$ of cases \\
\hline $20-28$ & 100 & 22.99 \\
\hline $28-32$ & 78 & 17.93 \\
\hline $32-38$ & 65 & 14.94 \\
\hline $38-40$ & 156 & 35.86 \\
\hline Post-dated & 36 & 8.27 \\
\hline
\end{tabular}

Table 7 reveals that majority of IUFD foetuses were preterm i.e., $243(55.87 \%)$.

Table 8: Maternal risk factor associated with IUFD.

\begin{tabular}{|lll|}
\hline Maternal risk factor & No. of cases & \% of cases \\
\hline Pre eclampsia & 82 & 18.85 \\
\hline Essential hypertension & 10 & 2.2 \\
\hline Eclampsia & 7 & 1.6 \\
\hline Anaemia & 57 & 13.10 \\
\hline Labour complication & 12 & 2.17 \\
\hline Gestational diabetes & 4 & 0.9 \\
\hline Jaundice & 2 & 0.45 \\
\hline Heart disease & 1 & 0.22 \\
\hline UTI & 3 & 0.69 \\
\hline
\end{tabular}

According Table 8 amongst all maternal factors responsible for IUFD, hypertensive disorder of pregnancy was present in $99(22.75 \%)$ of the patients. This was found to be the most common cause responsible for IUFD and headed the list followed by maternal anaemia which was present in $57(13.1 \%)$ cases, followed by gestational diabetes in $0.9 \%$ cases, UTI in $0.69 \%$ cases, jaundice in $0.45 \%$ and heart disease in $0.22 \%$ cases.

Table 9: Foetal risk factor associated with IUFD.

\begin{tabular}{|lll|}
\hline Foetal risk factor & No. of cases & $\%$ of cases \\
\hline Congenital anomaly & 48 & 11.03 \\
\hline $\begin{array}{l}\text { IUGR with Severe } \\
\text { oligohydramnios }\end{array}$ & 31 & 7.12 \\
\hline Rh-isoimmunisation & 12 & 2.75 \\
\hline Multiple pregnancy & 5 & 1.14 \\
\hline
\end{tabular}

Table 9 Among all fetal risk factors, congenital anomaly was present in $48(11.03 \%)$ cases, being the most common cause followed by IUGR with oligohydramnios in $7.12 \%$ cases, $\mathrm{Rh}$ isoimmunisation was present in $2.75 \%$ pregnancies, while multifetal gestation was present in rest $1.14 \%$ of the patients.

Table 10: Placental risk factor associated with IUFD.

\begin{tabular}{|lll|}
\hline & No. of cases & $\%$ of cases \\
\hline $\begin{array}{l}\text { Accidental } \\
\text { haemorrhage }\end{array}$ & 31 & 7.12 \\
\hline Prolonged pregnancy & 36 & 8.27 \\
\hline PROM & 31 & 7.12 \\
\hline Placenta previa & 12 & 2.75 \\
\hline
\end{tabular}

As shown in Table 10 Amongst the placental risk factors, accidental haemorrhage and prolonged pregnancy constituted the bulk followed by premature rupture of membranes (PROM) and placenta previa. More than one risk factor was identifiable in $18(4.13 \%)$ cases and in rest $46(10.57 \%)$ no obvious cause could be identified.

Table 11: Distribution of cases according to method of delivery.

\begin{tabular}{|lll|}
\hline Method of delivery & No. of cases & $\%$ of cases \\
\hline Induction & 195 & 44.82 \\
\hline Spontaneous & 174 & 40 \\
\hline Operative & 66 & 15.17 \\
\hline
\end{tabular}

As per Table 11, Out of 435 IUFDs 174 (40\%) had spontaneous onset of labour, 195 patients (44.82\%) needed induction of labour and 50 patients $(12.18 \%)$ underwent LSCS. Indications for lower segment caesarean section (LSCS) were placenta previa, severe abruption placentae, obstructed labour, previous two LSCS, eclampsia and history of classical caesarean section.

Table 12 shows that $369(84.82 \%)$ patient delivered vaginally and operative delivery occurred in $66(15.18 \%)$ 
patients, amongst them 50 were LSCS, 3 were hysterotomy and 13 cases underwent exploratory laparotomy for repair of rupture uterus, and one had forceps delivery.

\section{Table 12: Distribution of cases according mode of} delivery.

\begin{tabular}{|lll|}
\hline Mode of delivery & No. of cases & $\%$ of cases \\
\hline Vaginal & 369 & 84.82 \\
\hline Operative & 66 & 15.88 \\
\hline LSCS & $(50)$ & \\
\hline Hysterotomy & $(6)$ & \\
\hline $\begin{array}{l}\text { Laparotomy for } \\
\text { rupture }\end{array}$ & $(13)$ & \\
\hline
\end{tabular}

Table 13: Distribution according to gender.

\begin{tabular}{|lll|}
\hline Gender & No. & \% of cases \\
\hline Male & 218 & 50.11 \\
\hline Female & 217 & 49.89 \\
\hline
\end{tabular}

According Table 13, $218(50.11 \%)$ were delivered as male and 217 (49.19\%) were female.

\section{DISCUSSION}

The actual incidence of IUFD is not possible due to underreporting of all cases. ${ }^{1}$ According to this study, the incidence of IUFD is $37.45 / 1000$ live births. ${ }^{2-4,6}$ The incidence of IUFD reported from western countries ranges from $4.7 \%$ to $12.0 \%$. This is lower than that observed in present study. A very high incidence of fetal demise was obtained in present study because our institute is the single largest tertiary centre catering the western Rajasthan, so most of the complicated and highrisk cases are referred to our centre. The incidence rate reported from various centres in India is higher 24.4$41.9 \% .^{2-4,6}$ The other reason could be a high number of unsupervised pregnancy due to various reasons like illiteracy, low socioeconomic status and the paucity of monitoring facilities in rural areas.

Nutritional deficiency and anaemia are leading cause of poor pregnancy outcome. Majority of our patients were anaemic. The increased risk of fetal death is present amongst the teenage group and older women. The western studies also showed increased risk of IUFD in women over 35 years of age. In our study, however, the fetal deaths were more in the age group of 20-30 years. This is because most of the women in India complete the family before 35 years of age.

Increased risk of IUFDs is seen amongst primigravidas. ${ }^{5,6}$ The incidence is higher amongst women with minimal or no antenatal care. This is also reflected in our study where the rates were highest amongst the unsupervised pregnancies. The incidence of APH in our study was 43 $(9.87 \%)$, which was lower than that reported in other studies. The incidence of intrauterine growth retardation in our study was $31(7.12 \%)$. The other studies have reported the incidence from $2.2 \%$ to $18.4 \%$.

The incidence of gestational hypertension in this study was $22.75 \%$ which is similar to that reported in other studies. $^{7}$ The incidence of congenital malformation was $11.03 \%$ which was also similar to that reported from other studies. $^{7-10}$

\section{CONCLUSION}

Hypertensive disorder of pregnancy, anaemia, APH, congenital anomalies were leading causes of IUFD. Majority of women who had IUFD were unbooked and had emergency admission and had not received adequate antenatal care. The associated risk factors in a community seems to be preventable, hence we should pay attention to health education with emphasis on antenatal care and its benefit, improved periconceptional environment, nutrition, micronutrient status especially iron and folic acid intake.

Identification of high risk cases and their timely referral to higher centres may save the baby. Patient compliance is important in reducing most of these preventable foetal losses. However unexplained cause of IUFD seen in 46 $(10.57 \%)$ cases. In case of unexplained IUFD fetal autopsy, placental and membrane examination could be helpful for finding out causes. Patients should be counselled in a positive way for fetal biopsy so as to explore unexplained IUFD and plan future pregnancy accordingly.

\section{ACKNOWLEDGMENTS}

Authors would like to thank entire team of obstetricians of Umaid Hospital, operation theatre and ICU staff, patients who participated in the study for their help and co-operation.

\section{Funding: No funding sources \\ Conflict of interest: None declared \\ Ethical approval: Not required}

\section{REFERENCES}

1. Stanton C, LawnJ E, Rahman H, WilczynskaKetende K, Hill K. Stillbirthrates:Delivering estimates in 190 countries. Lancet 2006;367:148794.

2. Patel S, Thaker R, Shah P, Majumder S. Study of causes and complications of intra uterine fetal death (IUFD). Int J Reprod Contracept Obstet Gynecol. 2014;3:931-5.

3. Mathuriya G, Bunkar N. Evaluation of intrauterine foetal death at tertiary care centre. Inter J Medical Sci Res Prac. 2015;2(3):139-42.

4. Sharma S, Sidhu H, Kaur S. Analytical study of intrauterine fetal death cases and associated maternal 
conditions. Int J Appl Basic Med Res. 2016;6(1):113.

5. Mathuriya G, Bunkar N. Evaluation of intrauterine foetal death at tertiary care center. Heart disease. 2015;2:0-39.

6. Dasgupta S, Saha I, Mandal AK. A study on profile of stillbirths. J Indian Med Assoc. 1997;95:175-8.

7. Misra PK, Thakur S, Kumar A, Tandon S. Perinatal mortality in rural India with special reference to high risk pregnancies. J Trop Pediatr. 1993;39:41-4.

8. Hovatta O, Lipasti A, Rapola J, Karjalainen O. Causes of stillbirth: A clinicopathological study of 243 patients. Br J Obstet Gynecol. 1983;90:691-6.
9. Machin GA. A perinatal mortality survey in southeast London, 1970-73: The pathological findings in 726 necropsies. J Clin Pathol. 1975;28:428-34.

10. Anjali C, Vineeta G. Epidemiology of intrauterine fetal deaths:a study in tertiary referral centre in Uttarakhand. IOSR-JDMSO. 2014;13(3):3-6.

Cite this article as: Gehlot $\mathrm{H}$, Nagar GG, Sharma S, Yadav OP. A prospective analytical study of intrauterine fetal death cases and associated maternal condition at a tertiary centre. Int J Reprod Contracept Obstet Gynecol 2017;6:3392-6. 